\title{
Turbulence Combined Convective Heat Transfer and Nanofluids Flows over Double Forward Facing Steps
}

\author{
Omar Hussein ${ }^{1,2}$, Khairul Habib ${ }^{2}$, Mohammad Nasif $^{2}$, Ali $_{\text {Muhsan }}^{3}$, Balaji Bakthavatchalam $^{2}$ \\ ${ }^{1}$ College of Applied Engineering, Department of Mechanical Engineering,, Tikrit, Iraq. \\ ${ }^{2}$ College of Engineering, Department of Mechanical Engineering, 32610 Seri Iskandar, Perak Darul \\ Ridzuan, Malaysia \\ ${ }^{3}$ College of Engineering, Department of Petroleum Engineering, 32610 Seri Iskandar, Perak Darul \\ Ridzuan, Malaysia
}

\begin{abstract}
Predictions are reported for mixed convection using various types of nanofluids over forward-facing double steps in a duct. The continuity, momentum and energy equations are discretized and the simple algorithm is applied to link the pressure and flow fields inside the domain. Different types of nanoparticles $\mathrm{Al}_{2} \mathrm{O}_{3}, \mathrm{CuO}, \mathrm{SiO}_{2}$ and $\mathrm{ZnO}$, with different volume fractions in range of $1-4 \%$ are investigated to identify their effects on the heat transfer and fluid characteristics. Numerical investigations are conducted using finite volume method. The results indicate that $\mathrm{SiO}_{2}$-water has the highest Nusselt number followed by $\mathrm{Al}_{2} \mathrm{O}_{3}$-water, $\mathrm{CuO}$-water and $\mathrm{ZnO}$-water. The Nusselt number increases as the volume fraction increases but decreases as the nanoparticles diameter increases.
\end{abstract}

\section{Introduction}

Many research studies combined convection heat transfer in forward double facing steps into the flow that uses a subject interest of this study. However, performing experiments to investigate its thermal behavior is sometimes expensive especially when nanomaterials were utilized to improve the thermal performance. Hence, utilizing computer simulation may be more feasibe to predict the thermal behaviour of mixed convection in forward facing double steps configuration. One of the ways to increase heat transfer in the separated regions is to use nanofluid. Nanofluid is a liquid that contains suspended nanoparticles such as metals and oxides. These nanoparticles remain suspended in the base fluid. Therefore, it can not cause significant increase in pressure drop in the flow field. Previous studies have shown that nanofluids exhibit enhanced thermal properties, such as higher thermal conductivity and convective heat transfer coefficients compared to the base fluid. Daungthongsuk and Wongwises [1], Hirofumi et al. [2] investigated developed

\footnotetext{
${ }^{1}$ Corresponding author: Omarh4783@gmail.com
} 
the flow system turbulent of the boundary layer over a forward-facing step. It has been shown that a significant counter-gradient diffusion phenomena (CDP) has been observed in the step near the wall. Yilmaz and Oztop [3] performed computer simulation of heat transfer under convection for double forward facing step to flow. The standard $k-\varepsilon$ turbulence model is used to obtain modeling turbulence flow. Impact fluid flow steps, lengths of steps and Reynolds number on heat transfer and height are investigated. It has been noted that heat transfer and turbulent intensity were raised with a higher Re.

Laminar flow problems with geometry of backward-facing step that move on mixed convection have been widely investigated in the past, numerically and experimentally by several researchers $[4,5,6]$. The problem of mixed convection laminar flows through the forward steps has been getting a little attention and rarely investigated.

Whereby, a mixed constitutional study over forward steps using nanofluid in twodimensional horizontal verification under uniform the boundary of heat flux as if it not investigated in the past and this has motivated the current study.

Thus, the present work investigates numerically the utilization of various kinds of nanofluids such as $\left(\mathrm{Al}_{2} \mathrm{O}_{3}, \mathrm{CuO}, \mathrm{SiO}_{2}\right.$, and $\left.\mathrm{ZnO}\right)$ with different volume fraction in forward facing double steps flow. The effect of Nusselt number are studied and reported to illustrate effects nanofluids on these parameters.

\section{Numerical model}

\subsection{Physical Model}

As the forward facing step (FFS) is placed in the horizontal channel as shown in Figure1 as a representative of a mix convection flow. The downstream steps (a) is maintained at uniform heat flux $\left(\mathrm{q}_{\mathrm{x}}\right)$, while the straight wall that forms the other side of the channel is maintained at constant temperature equal to the inlet temperature $\left(T_{i n}\right)$. The walls down steps $(b, c)$ and the steps themselves $\left(\mathrm{h}_{1}, \mathrm{~h}_{2}\right)$ are considered as adiabatic.

The nanofluid at the horizontal channel inlet is considered to be hydrodynamic stable and the fully developed is achieved at the corner of the step, and the flow gradient at all quantities at the outlet hole channel is equal to be zero.

This study only relates to turbulent flow. Nano-additives and type of base fluid (i.e. water) are assumed to have thermal equilibrium and no slip conditions occurs. Fluid flow is assumed to be Newtonian and cannot be compressible. Radiation heat transfer and dissipation of viscous terms are ignored. Internal heat generation is not carried out in the present study.

The thermo physical properties of the nanofluid are constant and are only affected by buoyant force of mixed, which means that the force of the body acting on the fluid is the gravity; its density is altered and can be modeled enough by Boussinesq estimate. ANSYS FLUENT CFD software has been used in current studies to implement the simulation.

$$
\rho-\rho_{\infty}=\left(T-T_{\infty}\right)
$$

Where, $\rho$ is density, $\mathrm{T}$ is temperature; $\rho_{\infty}$ and $T_{\infty}$ are ambient density and temperature, respectively. Once these assumptions are made, it is possible to obtain the nanofluids flow administration equation through a forward double facing step. 


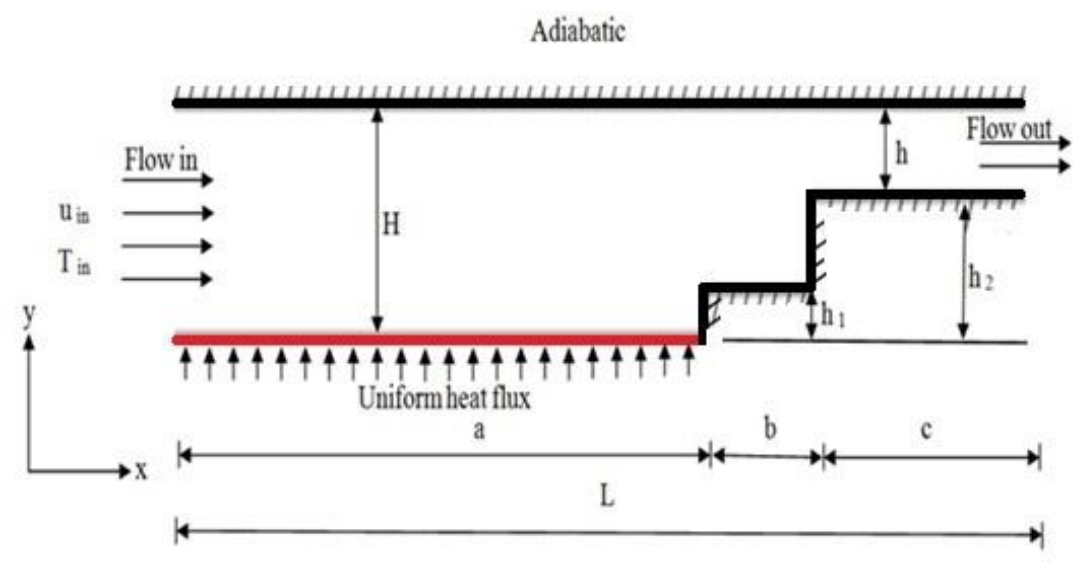

Fig.1.Schematic Diagram for 2D FFS in Channel Flow.

\subsection{Governing equations}

As mentioned, Computational fluid dynamics (CFD) simulation is carried out in this study to investigate the effect of nanoparticles in forward facing double steps flow on heat transfer enhancement. The governing equations solved are continuity, momentum, and energy equation. Using the Boussinesq approximation and ignoring the viscosity effects governing equations for two dimensional mixed convection turbulent flow incompressible can be written as follows [7]:

The continuity equation

$$
\frac{\partial U}{\partial X}+\frac{\partial V}{\partial Y}=0
$$

Turbulence Model Equations

The turbulence model employed for turbulence flow modeling is the standard $k$ - $\varepsilon$ model. The turbulence kinetic energy, $\mathrm{k}$, and the dissipation rate, $\varepsilon$, are determined using the following transport equations [7]:

$$
\begin{gathered}
\frac{\partial}{\partial x}(\rho k u)=\frac{\partial}{\partial y}\left(\left[\mu+\frac{\mu_{t}}{\sigma_{k}} \cdot \frac{\partial k}{\partial y}\right]\right)+G_{k}-\rho \varepsilon \\
\frac{\partial}{\partial x}(\rho \varepsilon u)=\frac{\partial}{\partial y}\left[\left(\mu+\frac{\mu_{t}}{\sigma_{k}}\right) \frac{\partial \varepsilon}{\partial y}\right]+C_{1 \varepsilon} \frac{\varepsilon}{k}\left(G_{k}-C_{3 \varepsilon} G_{b}\right)-C_{2 \varepsilon} \rho \frac{\varepsilon^{2}}{k} \\
(a) \mu_{t}=\rho \cdot C_{p} \frac{k^{2}}{\varepsilon},(b) G_{k}=\rho v^{\prime} u \frac{\partial v}{\partial x}
\end{gathered}
$$

\subsection{Boundary condition}

The turbulent heat transfer problems considered in the present work are shown schematically in Figure1. It is a horizontal channel with multiple steps. The top wall and steps are isolated, while the lower wall has heat flux that is hotter than the inflow temperature. The $2 \mathrm{D}$, steadystate, incompressible turbulent flows are considered. This horizontal channel has doubled 
steps at heights $h_{1}$ and $h_{2}$. Height and length of the channel are depicted by $\mathrm{H}$ and L (Figure1). The length of the steps $\mathrm{b}$ and $\mathrm{c}$ are also shown in Figure1.

\subsection{Code Validations and Grid Testing}

\subsubsection{Code validations}

The validation of mixed convection flow in this model is conducted with the results of Hong et al. [4]. The Reynolds number is maintained constant at $R e=100$ and uniform heat flux is fixed at $\mathrm{q}_{\mathrm{w}}=200 \mathrm{~W} / \mathrm{m}^{2}$ for different inclination angles $\left(0^{\circ}, 90^{\circ}, 135^{\circ}, 180^{\circ}, 315^{\circ}\right)$. As seen in Figure 2 the presented results indicate a good agreement with those of Hong et al. [4].

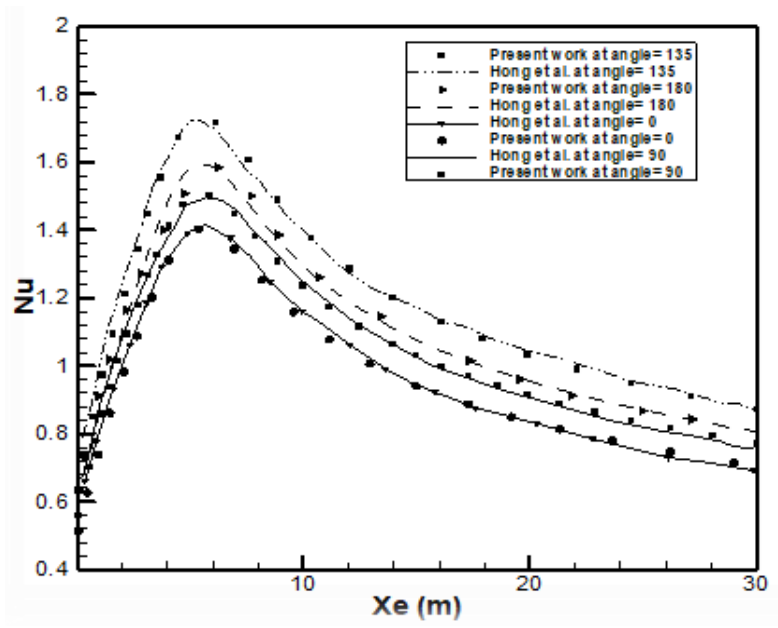

Fig. 2. Comparison of Nusselt Number with the Results of Hong et al. [4] $(\mathrm{S}=4.8 \mathrm{~mm}$, and $\mathrm{ER}=2)$ for $\operatorname{Re}=100$, and $\mathrm{q}_{\mathrm{w}}=200 \mathrm{~W} / \mathrm{m}^{2}$ on Different Inclination Angles.

\subsection{Thermophysical Properties of Nanofluids}

To run a simulation for nanofluids, the effective thermophysical properties of nanofluids must first be calculated. In this case, the nanoparticles are used $\mathrm{Al}_{2} \mathrm{O}_{3}, \mathrm{CuO}, \mathrm{SiO}_{2}$ and $\mathrm{ZnO}$. The main properties of the nanomaterials in this simulation are the effective thermal conductivity ( $\left.k_{\text {eff }}\right)$, effective dynamic viscosity $\left(\mu_{e f f}\right)$, effective mass density $\left(\rho_{\text {eff }}\right)$, effective coefficient of thermal expansion $\left(\beta_{\text {eff }}\right)$ and effective specific heat $\left(\mathrm{C}_{\text {peff }}\right)$. The effective of thermophysical properties are calculated using the theory of mixing.

Effective Thermal Conductivity:

By using the Brownian nanoparticles motion forward double steps; the effective thermal conductivity can be obtained by using the following empirical correlations [8]:

$$
k_{\text {eff }}=k_{\text {Static }}+k_{\text {Brownian }}
$$


Static Thermal Conductivity

$$
k_{\text {static }}=k_{b f}\left[\frac{k_{n p}+2 k_{b f}-2\left(k_{b f}-k_{n p}\right) \phi}{k_{n p}+2 k b f+\left(k_{b f}-k_{n p}\right) \phi}\right]
$$

Brownian Thermal Conductivity:

$$
k_{\text {Brownian }}=5 \times 10^{4} \beta \phi \rho_{b f} c_{p}, b f \sqrt{\frac{k T}{2 \rho_{n p}}} . f(T, \phi)
$$

\section{Results and discussion}

\subsection{The effect of different types of nanofluids}

\subsubsection{Nusselt number}

In this section, four different types of nanoparticles, $\mathrm{Al}_{2} \mathrm{O}_{3}, \mathrm{CuO}, \mathrm{SiO}_{2}$ and $\mathrm{ZnO}$ and pure water as a base fluid at local $\mathrm{Nu}$ above the lower wall are shown. Nusselt numbers for different nanofluids at $\mathrm{Re}=80000$, while volume concentration and particle diameter are $4 \%$ and $20 \mathrm{~nm}$ are shown in Figure 3. As can be seen same trends of Nusselt numbers are obtained for all nanofluids. But in terms of comparing the four kinds of nanofluids, it is clear that nanofluid with $\mathrm{SiO}_{2}$ has the highest Nu number, followed by $\mathrm{Al}_{2} \mathrm{O}_{3}, \mathrm{CuO}$ and $\mathrm{ZnO}$ respectively. Nanofluid with higher Prandtl numbers has higher Nusselt numbers along the heated. The base fluid with $\mathrm{SiO}_{2}$ nanoparticles has the highest Nusselt number value among all nanofluids, because the highest thermal properties compared to other conventional fluid are investigated, followed by $\mathrm{Al}_{2} \mathrm{O}_{3}$ then $\mathrm{ZnO}$ and finally $\mathrm{CuO}$.

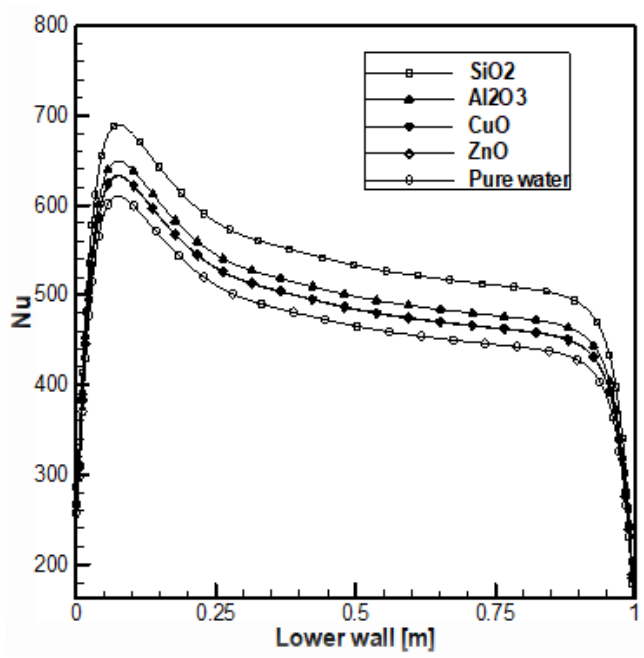

Fig. 3. Local Nusselt Number for Different Nanofluids Along the Heated Wall Re $=80000$ and with $\mathrm{d}_{\mathrm{p}}=20 \mathrm{~nm}$ and $\varnothing=4 \%$. 


\subsection{The effect of different volume fractions of nanoparticles}

\subsubsection{Nusselt number}

The volume fraction of nanoparticles represents the number of constituent nanoparticles divided by the volume of all constituents of the mixture prior to mixing.

Volume fraction of nanofluids is the ratio of nanoparticles suspended in the base fluids. Thus, pure water has zero volume fractions. In this study the volume fraction was in the range of 0 $-4 \%$ with $\mathrm{Re}=80000$ and nanoparticle diameter $\mathrm{d}_{\mathrm{p}}=20 \mathrm{~nm}$ of $\mathrm{SiO}_{2}$ nanofluid is studied and Nusselt number for these condition is shown in Figure 4. As seen, nanofluids with higher volume fraction achieved grater heat transfer enhancement. Because increasing the volume fraction causes the increased thermal conductivity of the fluid and hence the higher heat transfer increase is achieved at a higher volume fraction.

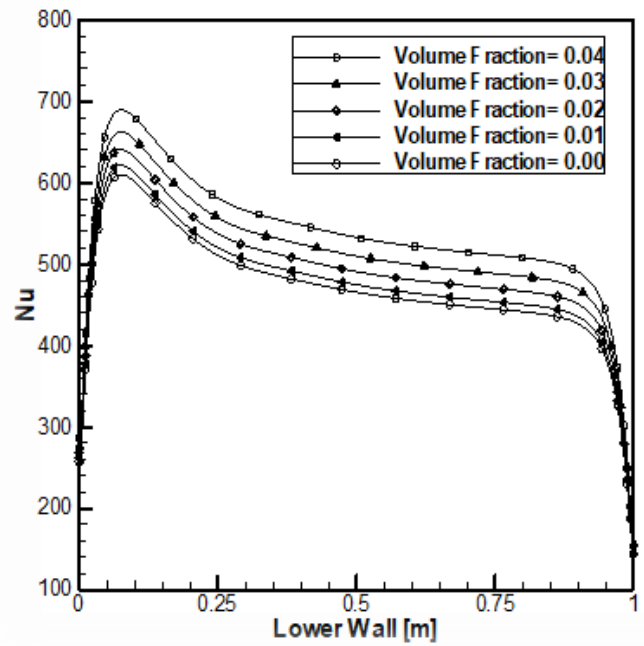

Fig.4. Local Nusselt Number for Different Volume Fractions Along the Heated Wall of $\mathrm{SiO}_{2}$ Nanofluids Flow with $\mathrm{Re}=80000$ at $\mathrm{d}_{\mathrm{p}}=20 \mathrm{~nm}$.

\section{Conclusion}

Numerical simulation of combined convection heat transfer in double steps forward horizontally using nanofluid has been presented. Emphasis is given on the increase in heat transfer caused by various parameters, including different nanofluids $\mathrm{Al}_{2} \mathrm{O}_{3}, \mathrm{CuO}, \mathrm{SiO}_{2}$ and $\mathrm{ZnO}$ with base fluid (water), and volume fraction (concentration) in the range of $0 \leq \varnothing \leq 4 \%$. The investigation was carried out numerically using ANSYS FLUENT CFD software. The results showed that $\mathrm{SiO}_{2}$ gave the highest $\mathrm{Nu}$ followed by $\mathrm{Al}_{2} \mathrm{O}_{3}, \mathrm{CuO}$ and $\mathrm{ZnO}$, respectively while pure water gave the lowest $\mathrm{Nu}$ and Nusselt number was increased by increasing the volume fraction of nanoparticles.

\section{References}

1. W. Daungthongsuk, and S. Wongwises, Renewable and Sustainable Energy Reviews 11, (5) (2007) .

2. H. Hattori, Y. Nagano, Int J Heat Mass Transf, vol. 31, (2010).

3. I. Yilmaz, H. F. Öztop, INT COMMUN HEAT MASS vol.33, (2006). 
4. B. Hong, B. F. Armaly, T. S. Chen, Int J Heat Mass Transf, vol. 36, (1993).

5. H. A. Mohammed, \& O.A.Hussein. J Nanotechnol Eng Med, 5(1), (2014).

6. O. A. Hussein.T.J.E.S., 24(1), (2017).

7. E. Abu-Nada, Int J Heat Mass Transf, 29(1) (2008).

8. B. Ghasemim S.M. INT J THERM SCI, vol. 49, (2010). 